\title{
Produção de biofertilizante, adubo orgânico e biogás para agricultura familiar
}

\author{
Production bio-Fertilizer, organic compost and biogas for smallholder agriculture
}

\author{
Sâmia Mirelly Alexandre de Assis Marques'; Francisco José da Silva Júnior²; Maria Kalyane Duarte Montei- \\ ro ${ }^{3}$; Allan Sarmento Vieira ${ }^{4}$; Ana Flávia Albuquerque Ventura ${ }^{5}$; Raul Ventura Júnior ${ }^{6}$ \\ 1, 2, 3 Alunos do Curso de Graduação em Ciências Contábeis, Universidade Federal de Campina Grande, Campus Sousa-PB, Brasil \\ 4;5;6 Professores, Universidade Federal de Campina Grande, Campus Sousa-PB, Brasil
}

\section{Resumo}

Este trabalho propõe o desenvolvimento de um biodigestor portátil, utilizando na sua composição materiais recicláveis. Tem como objetivo minimizar os custos de implementação para o pequeno produtor rural e, consequentemente, ajudar na preservação do meio ambiente, reduzindo a emissão de gás carbono, conforme previsto no Protocolo de Kyoto. Apesar de ser uma tecnologia bastante difundida na região sul do Brasil, os modelos propostos na literatura ainda apresentam alto custo de instalação, o que torna inviável para a agricultura familiar. É notório que os investimentos nesse tipo de tecnologia são necessários, já que os benefícios visam aumentar a equidade social e a qualidade do meio ambiente. A inovação está em propor um biodigestor que utiliza material reciclável na sua estrutura e que pode ser deslocado na propriedade rural. Com esse biodigestor em mãos, será feita uma pesquisa tecnológica a fim de averiguar a adequação na realidade do sertão paraibano e os benefícios gerados para a agricultura familiar. Em seguida, será utilizado um equipamento de detecção do gás metano, com o intuito de acompanhar a sua evolução. O resultado apresenta um equipamento versátil, de baixo custo e de grande utilidade para a agricultura familiar. Assim, o biodigestor proposto é um produto importante para melhorar a qualidade de vida da comunidade local, já que propõe gerar renda extra, maximizar equidade social e minimizar os impactos negativos na natureza.

Palavras-chave: Biodigestor; Biogás; Meio Ambiente.

\begin{abstract}
This paper proposes the development of a portable digester that uses recyclable materials in their composition, and which aims to minimize the costs of implementation for small rural producers and consequently help in preserving the environment, reducing carbon gas emissions under the Kyoto Protocol. Despite being a technology quite widespread in southern Brazil, the models proposed in the literature, still have high costs at the facility, making it infeasible to your installation to family agriculture. Is notorious, that investments in technology are needed, since the benefits to increase social equity and environmental quality. Innovation is to propose a biodigester that uses recyclable materials in its structure and can be moved to any location of the country estate. With this bio-digester at hand, will be carried out a survey of technology, in order to ascertain its effective to suit the reality of Paraibano and the benefits generated for family farming. Next you'll be using a methane gas detection equipment, in order to follow the evolution of it. The result shows a quite versatile, inexpensive and very useful for family farming. However the biodigestor proposed is a product essential in improving the quality of life of the local community, since they propose to generate extra income, maximizing social equity and minimizing the negative impacts on nature.
\end{abstract}

Keywords: Biodigester; Biogas; Environment. 


\section{INTRODUÇÃO}

O aquecimento global é uma das maiores preocupações da atualidade, possuindo efeitos econômicos e não econômicos. Pode influenciar setores do mercado como a agricultura, o turismo, a piscicultura, pode provocar o aumento do nível do mar e a mudança na qualidade e quantidade de água doce. Com relação aos impactos não econômicos podem ser citados: a saúde, o lazer, a perda da qualidade dos ecossistemas e a perda de culturas (WORLD BANK, 2008b).

A degradação ambiental, sem a utilização de uma gestão eficiente, causa prejuízos muitas vezes imensuráveis, contaminando o ar, o solo e a água. Um exemplo comum é a emissão do gás metano, proveniente de lixão e granjas (suínos, caprinos, ovinos, etc). Nasir et al. (2012) afirmaram que na literatura existem vários métodos para gerenciar esses resíduos provenientes da degradação, em especial a digestão anaeróbica (biodigestores) por ser um processo eficiente.

Os biodigestores podem ser definidos como um conjunto de microrganismos que degrada compostos orgânicos presentes no resíduo até produzir metano e dióxido de carbono. Os nutrientes contidos nos dejetos garantem ainda a reprodução dos microrganismos, que também produzirão biofertilizantes e adubo orgânico, além do biogás (ORRICO JUNIOR et al., 2012).

A ideia da economia dos recursos naturais surgiu recentemente, e ganhou projeção depois da conferência Rio+20. A economia verde pode ser definida como aquela que "resulta em melhoria do bem-estar humano e equidade social, ao mesmo tempo em que reduz significativamente os riscos ambientais e a escassez ecológica" (United Nations..., 2011, p.16). A economia verde possui baixas emissões de carbono, eficiência no uso de recursos e inclusão social (DINIZ et al., 2012). Além disso, deve-se respeitar o grau de elasticidade dos ecossistemas, ou seja, o quanto se pode utilizar dos recursos disponíveis sem degradar o meio ambiente. Percebe-se então que preservar o meio ambiente é um bom negócio. Esse pensamento não é só de ecologistas idealistas, e sim afirmações de grandes empresas e de comunidades locais. Reduzir os custos com a eliminação dos desperdícios, desenvolvendo tecnologias limpas e baratas e reciclando insumos, não são princípios apenas requisitos da gestão ambiental, mas condições de sobrevivência empresarial (ANDREOLI, 2002). Com base nessas afirmações, a preocupação da sociedade com o meio ambiente fez surgir à gestão ambiental, que é entendida como um conjunto de normas, ações administrativas e operacionais, que tem como objetivo minimizar ou eliminar os danos ambientais causados pela intervenção do homem, que podem refletir nos negócios das empresas e da sociedade.

Para Prati (2010), as tecnologias que promovem a obtenção de fontes renováveis são atrativas não só pelas vantagens ambientais, mas também pela melhoria dos aspectos sociais e econômicos. A possibilidade de criar estruturas descentralizadas e pequenas escalas é fundamental na promoção do desenvolvimento sustentável da região.

Uma das tecnologias bastante difundidas é a utilização de biodigestores, foco deste projeto. Os biodigestores podem ser definidos como câmeras que não contêm oxigênio, permitindo que determinadas bactérias decomponham os dejetos orgânicos, produzindo como produto final adubo orgânico, biofertilizantes e biogás.

Existem, ainda, diversos motivos para o desenvolvimento de um biodigestor, segundo Neves (2010), como a redução da carga de matéria orgânica lançada no meio ambiente, o controle da proliferação de moscas, a redução de odores ofensivos e desagradáveis, a diminuição da emissão de dióxido de carbono $\left(\mathrm{CO}_{2}\right)$ e metano $\left(\mathrm{CH}_{4}\right)$ na atmosfera através da queima, o aproveitamento de restos de natureza orgânica e, principalmente, o oferecimento de um destino a esses materiais. Além disso, é importante a conscientização da comunidade sobre os impactos ambientais da emissão de gases de efeito estufa (GEE) na atmosfera, bem como o seu possível agravante no aquecimento global.

O objetivo principal desta pesquisa é desenvolver um biodigestor de baixo custo a partir de materiais recicláveis, que seja capaz de produzir biogás, biofertilizante e adubo orgânico, adaptando a realidade sertaneja e ajudando a economia da agricultura familiar e a preservação do meio ambiente.

\section{METODOLOGIA}

\section{I QUANTO AOS PROCEDIMENTOS E AOS FINS}

O presente trabalho pode ser classificado como exploratório e descritivo, com pesquisa de campo. 
Isso porque envolve pesquisa bibliográfica, estudo de caso e estabelece relações entre as variáveis. As observações serão estabelecidas de forma direta, pois utiliza instrumentos com a finalidade de obter um equipamento que evidencia o alcance dos objetivos propostos.

Para Silva e Menezes (2001) a pesquisa descritiva tem como objetivo principal a descrição das características de determinada população ou fenômeno, bem como o estabelecimento de relações entre as variáveis, utilizando a coleta de informações ou qualquer modalidade de tratamento, ou evidenciando o estudo que fortalecerá o entendimento da tecnologia utilizada.

No desenvolvimento da pesquisa, optou-se pelo método hipotético-dedutivo. Essa opção se justifica porque o método escolhido permite ao pesquisador propor uma hipótese, e parte por meio da dedução para sua comprovação ou não. O material documentado e coletado, assim como as respectivas análises dos resultados, será organizado na forma de relatório final. Segundo Poper, K. apud Gil (1994), só o conhecimento é insuficiente para explicar determinada situação e as dificuldades do problema. Assim, são formuladas hipóteses que inferem as consequências a serem falseadas ou a confirmadas, que é o caso do hipotético-dedutivo.

\subsection{Coleta e ANÁlise dos Resultados}

Para Neves (1996), a abordagem dos métodos de investigação pode ser classificada como quali-quantitativa, já que apresenta características contrastantes quanto à forma e ênfase, embora não seja excludente. Essa classificação não significa que se deva optar por um ou outro. O pesquisador pode, ao desenvolver o seu estudo, utilizar os dois, usufruindo, por um lado, da vantagem de poder explicitar todos os passos da pesquisa e, por outro, da oportunidade de prevenir a interferência de sua subjetividade nas conclusões obtidas.

Com base neste contexto, as informações que podem ser levantadas e analisadas com relação a tecnologia do biodigestor são: artigos, livros, sites, demonstrações ambientais e financeiras de empresas que tenha projetos verdes, entre outros.

Para colocar em ação o objetivo proposto, será feito, inicialmente, uma pesquisa bibliográfica e exploratória para entender o funcionamento do biodigestor e levantar os principais modelos disponíveis na literatura, especificando o tipo material utilizado e mensurando seus custos de instalação.

Assim, inferiu-se a seguinte hipótese: "Será que os modelos de biodigestores disponíveis na literatura utilizam materiais recicláveis na sua estrutura, e seus custos de instalação são apropriados para agricultura familiar?". Com o intuito de averiguar se essa hipótese é verdadeira ou falsa, será feito um estudo minucioso nos tipos de biodigestores. Caso não se confirme, será proposto um modelo de biodigestor de baixo custo que utilize materiais recicláveis e que seja portátil. Em seguida serão feitas algumas análises, a fim de verificar a eficiência e a eficácia do modelo proposto.

A confecção do biodigestor proposto permitirá a mensuração dos benefícios gerados para a comunidade local e para o meio ambiente.

\subsection{Característica do biodigestor}

A ideia principal de um biodigestor é a criação de um meio anaeróbico favorável que terá duas partes básicas: a câmara de fermentação e o gasômetro. A câmara de fermentação é o local em que as bactérias realizarão todo o processo de produção de biogás e biofertilizantes, e o Gasômetro é reservado para o Biogás.

O biodigestor proposto será construído com três garrafões conectados, com orifícios de encaixe para os canos PVC, que alimentarão o sistema. Na lateral externa do último garrafão é conectado o cano de PVC $150 \mathrm{~mm}$, onde será feita a retirada dos dejetos orgânicos antigos para que haja reposição do novo. No primeiro garrafão é conectado, na parte mediana externa, um cano de PVC $75 \mathrm{~mm}$, pelo qual serão colocados os dejetos orgânicos já misturados com água; em seguida será conectada uma torneira na parte superior, que terá acesso ao biogás, e outra na parte inferior do sistema, dando acesso o biofertilizante. Para vedar totalmente o tambor e oferecer condições anaeróbicas para o processo serão usadas porcas torneadas com arruelas, veda rosca, Durepoxi e borracha de câmara de bicicleta, utilizados após o fechamento da tampa e em todos os locais em que foram instaladas as conexões. É importante lembrar alguns cuidados que devem ser tomados para obter o bom funcionamento do biodigestor, são eles: manter os animais presos durante uma parte do dia ou à noite, o ideal é que seja à noite; coletar pela manhã os dejetos orgânicos para serem depositados no coletor de entrada do biodigestor e, em seguida, vedar a entrada; e adicionar a água na proporção certa. O volume de água 
será determinado de acordo com o tipo do animal (bovino, ovino, caprino, etc). Na literatura existe o dimensionamento desta proporção, neste biodigestor foram utilizados dejetos de bovinos com a proporção de 1 a 1 , ou seja, a mesma quantidade de água e de dejetos. Além disso, os dejetos devem ser misturados com água para serem levados ao coletor de entrada do biodigestor; e deve-se esperar o tempo do processo de fermentação, em que teremos como produto final: adubo orgânico, biofertilizante e biogás. O tempo de retenção é dimensionado e estabelecido de acordo com o tipo dos produtos supracitados, que dependem da origem e do tipo de dejetos.

No seu manejo deve-se tomar cuidado com o local de instalação do biodigestor, pois ele é inflamável, apresentando risco de explosão. É necessário seguir algumas normas de segurança, dentre as quais podemos citar: o biodigestor deve ser instalado em local arejado; antes de utilizá-lo deve-se fazer a lavagem; colocar placas de indicação de perigo; deve ser manuseado por uma pessoa capacitada; e analisar se existem fugas de biogás nas instalações, que devem estar vedadas.

$\mathrm{O}$ abastecimento do biodigestor foi feito com fezes de bovinos leiteiros, tendo o cuidado de misturar o substrato com água, deixando totalmente uniforme. Essa mistura ocupa a metade do biodigestor, e a outra metade fica livre para a formação do biogás.

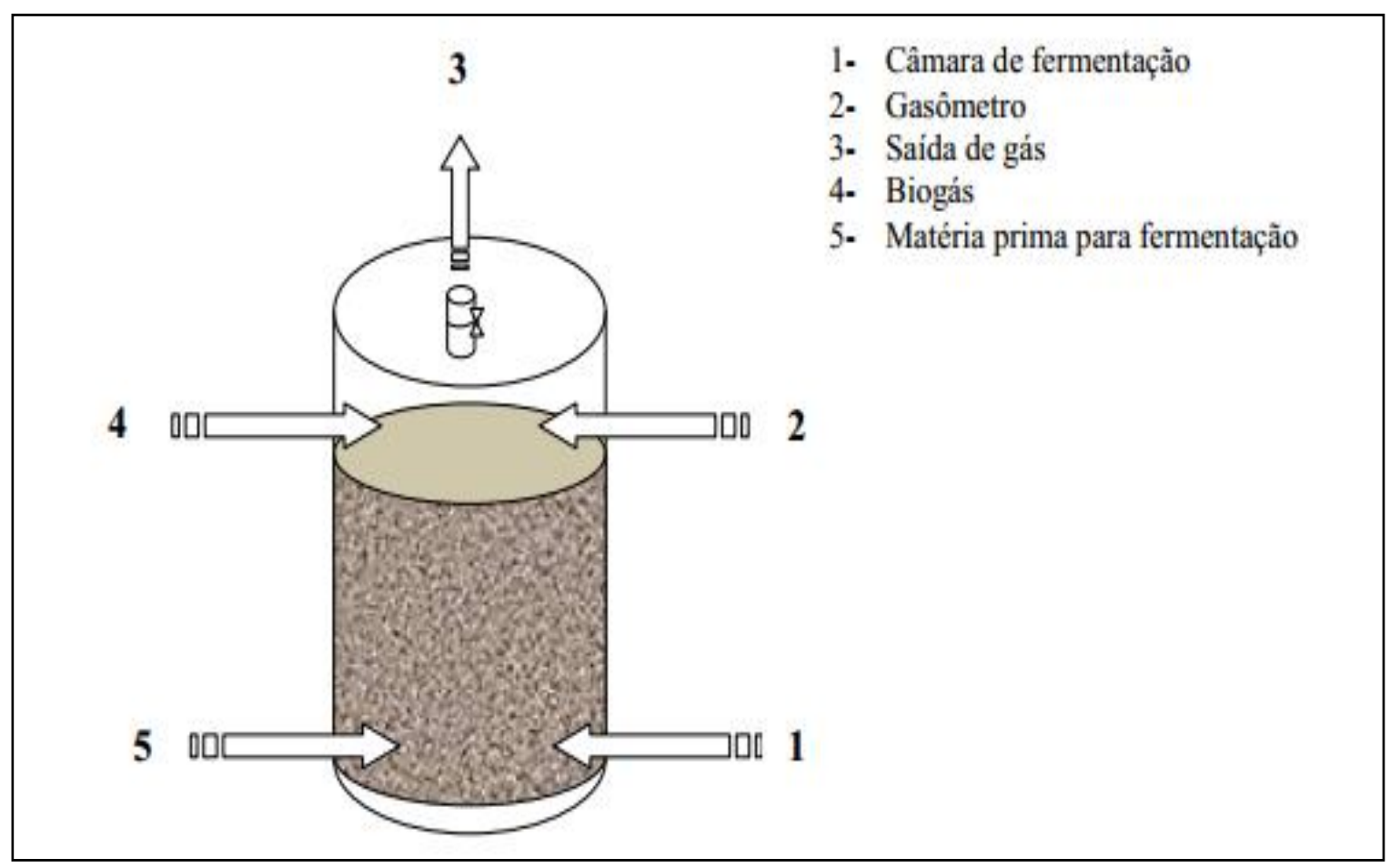

Figura 1: Esquema de um biodigestor.

Fonte: NEVES, 2010.

\section{RESULTADOS E DISCUSSÕES}

\section{I DESCRIÇÃO DO LOCAL E O CUSTO FINAL DO BIODIGESTOR}

O biodigestor foi instalado no perímetro irrigado de São Gonçalo, na cidade de Sousa do Estado da Paraíba, em um lote que faz parte da Associação de Moradores de São Gonçalo. Segundo dados do DNOCS (2013), possuem 452 pequenos produtores e uma área máxima irrigável de 4.100, têm principal sistema de reservatórios Engenheiro Ávidos e São Gonçalo, que juntos somam uma reserva hídrica de $299,60 \mathrm{hm}^{3}$. A cidade de Sousa-PB possui aproximadamente 20.096 bovinos que produzem em média 200,96 toneladas de esterco por dia, podendo produzir 72.345,60 de $\mathrm{m}^{3}$ de biogás por dia, o que pode ser negociado na bolsa de valores.

Com o intuito de minimizar esse impacto e gerar renda extra para o pequeno produtor, o novo biodigestor levou em sua estrutura principal vasilhames de água de 20 litros (vencidos), adquiridos de forma gratuita. 
A Tabela 1 mostra as especificações dos materiais necessários, e o quanto se gastou para confeccionar um biodigestor portátil.

Tabela 1. Especificação dos Materiais e Custo Total de um Biodigestor.

\begin{tabular}{|c|c|c|}
\hline & Quantidade & Valor R\$ \\
\hline Abraçadeira rosca $3 \times 4$ & 01 unidade & 0,90 \\
\hline Adaptador caixa água & 02 unidades & 9,90 \\
\hline Adesivo $17 \mathrm{cc}$ & 01 unidade & 0,17 \\
\hline Anel de vedação 100 mm & 01 unidade & 0,75 \\
\hline Anel de vedação 75 mm & 01 unidade & 0,70 \\
\hline Arco de Serra & 01 unidade & 11,15 \\
\hline Arruela & $0,04 \mathrm{Kg}$ & 0,69 \\
\hline Broca & 01 unidade & 2,55 \\
\hline Cap $100 \mathrm{~mm}$ & 01 unidade & 2,85 \\
\hline Cap 75mm & 01 unidade & 2,55 \\
\hline Cap. Sold $50 \mathrm{~mm}$ & 02 unidades & 5,10 \\
\hline Durepoxi & 06 unidades & 27,30 \\
\hline Luva & 04 unidades & 4,20 \\
\hline Mangueira para gás 8x4 & 1 metro & 1,59 \\
\hline Parafuso & 13 unidade & 0,39 \\
\hline Porca torneada & 13 unidade & 0,33 \\
\hline Serra & 01 unidade & 4,75 \\
\hline Torneira plástica & 02 unidades & 2,30 \\
\hline Tubo ESG. plástico 100 mm & 0,45 metros & 2,86 \\
\hline Tubo ESG. plástico 75 mm & 0,5 metros & 3,08 \\
\hline Válvula de fogão & 1 unidade & 15,00 \\
\hline Veda rosca & 01 unidade & 0,95 \\
\hline Valor Total & & $\mathrm{R} \$ 100,06$ \\
\hline
\end{tabular}


Nenhum dos pequenos produtores conhecia a tecnologia do biodigestor, e no início houve dúvidas sobre do projeto, por não acreditarem que a matéria orgânica poderia produzir biogás e biofertilizantes. Assim, o termo biogás dizia respeito principalmente à energia térmica e elétrica, do que o possível aproveitamento do esterco bovino para a sua produção. Porém, depois de esclarecidas as dúvidas, houve interesse confiança no projeto. As Figuras 2 e 3 mostram o resultado desta pesquisa, obtendo um biodigestor portátil que produz, a partir da fermentação anaeróbica de esterco bovino, biogás, biofertilizante e adubo orgânico.

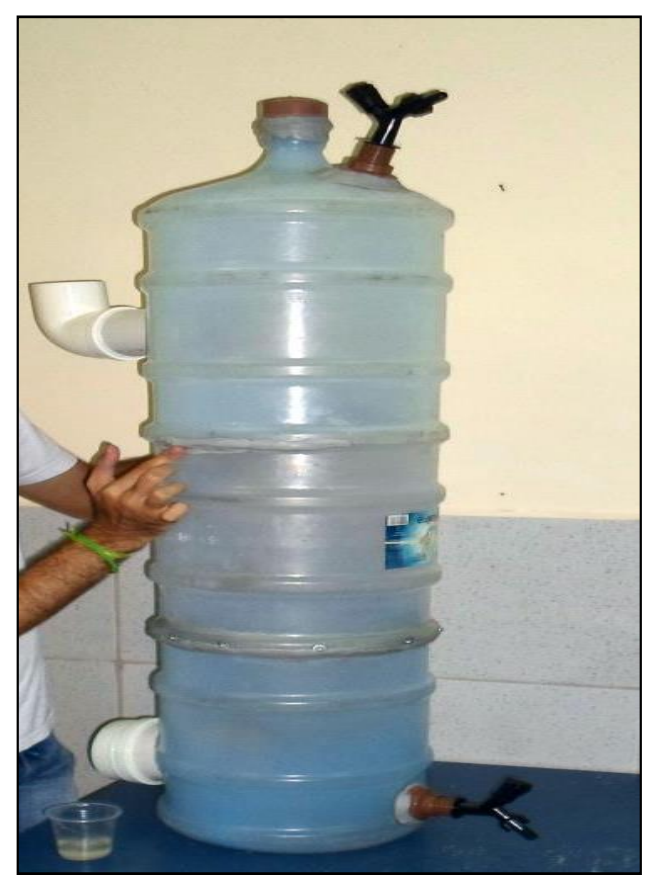

Figura 2. Biodigestor construído sem esterco bovino.

Fonte: Dados da Pesquisa (2014)

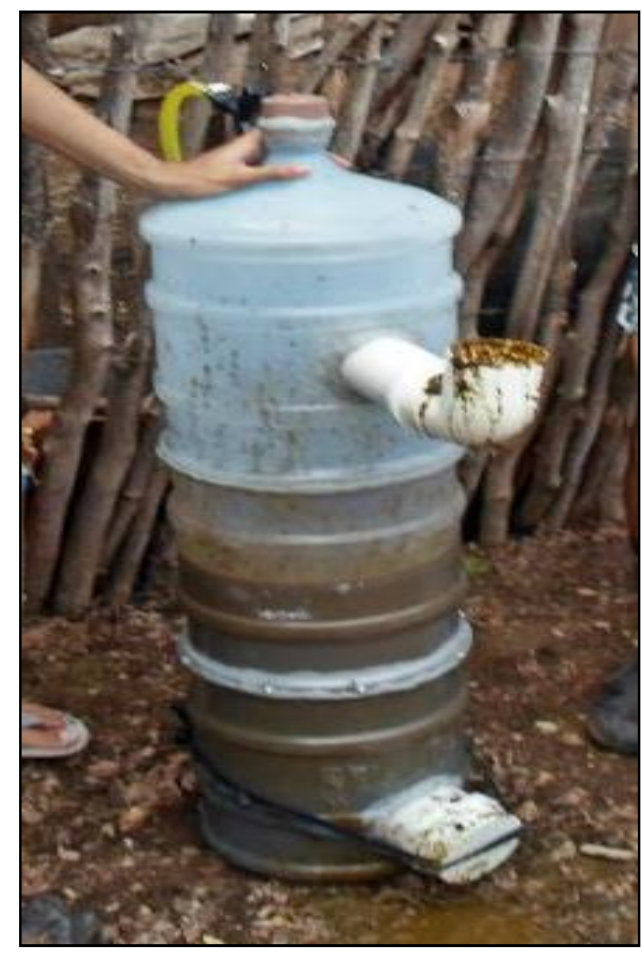

Figura 3. Biodigestor construído com esterco bovino.

Fonte: Dados da Pesquisa (2014) 
Durante os primeiros 10 dias, a válvula de alívio foi cuidadosamente aberta para a saída de dióxido de carbono, com o intuito de retirar as impurezas. Após 20 dias, tempo em que começa a produção do biogás a partir da biomassa, levou-se um equipamento que detecta o gás metano (Figura 4), comprado em São Paulo, podendo, assim, comprovar a sua produção.

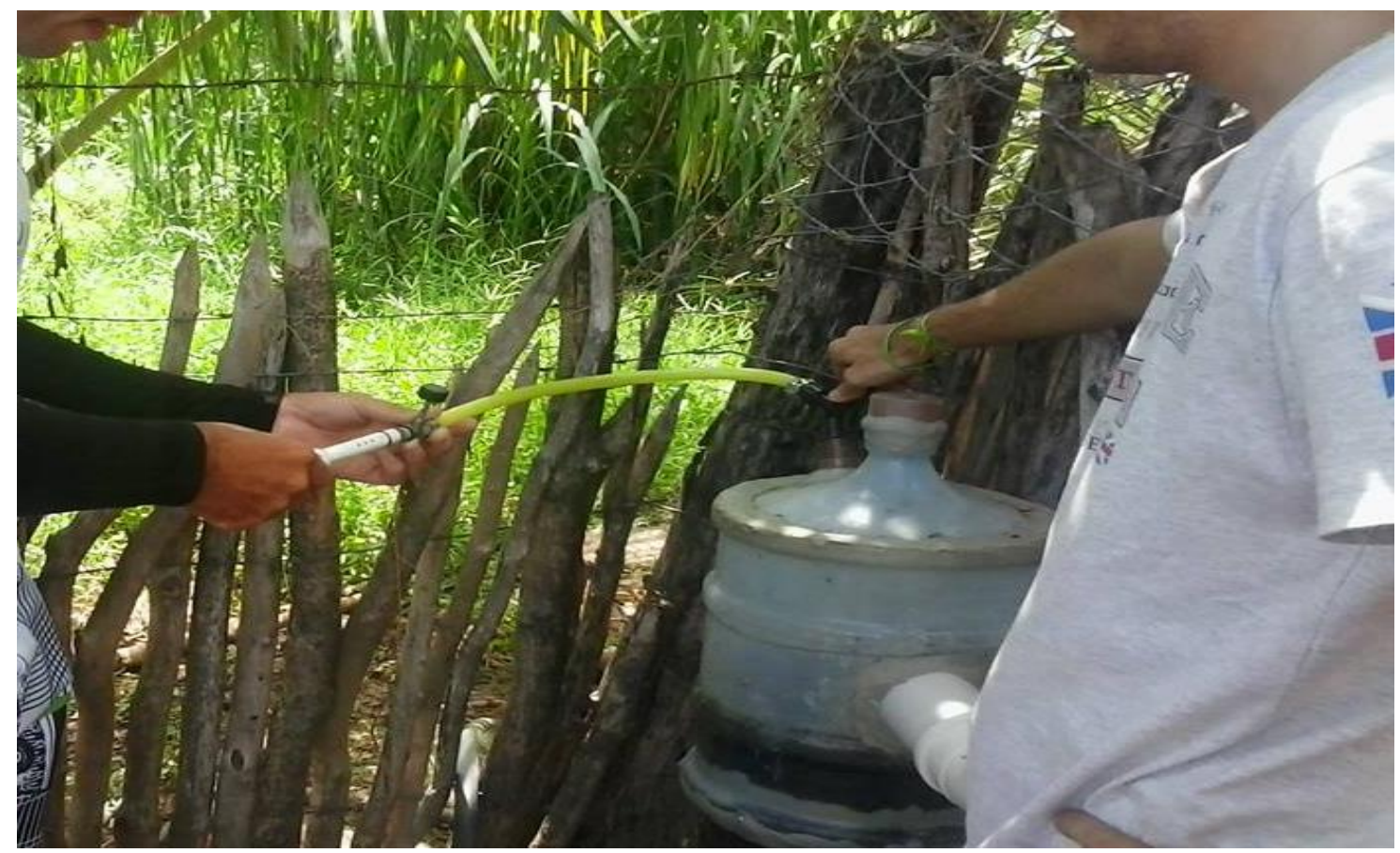

Figura 4. Detecção do biogás.

Fonte: Dados da Pesquisa (2014).

Fica assim comprovada a teoria descrita na literatura quanto à produção do biogás através de biodigestores, ressaltando que o custo vai ser sempre zero após o primeiro abastecimento, pois o sistema será o mesmo, com os gastos apenas da construção inicial. Conclui Neves (2010) que o sistema do biodigestor é contínuo, isto é, o biogás a partir da primeira descarga será produzido continuamente, com abastecimento diário de água e esterco, sempre haverá biogás no gasômetro.

O gás produzido pelo biodigestor pode ser utilizado para cozinhar, evitando o gasto com o botijão de gás, o biofertilizante pode ser utilizado para aumentar a proteção das hortas da propriedade contra possíveis pragas, e o adubo orgânico tem o objetivo de aumentar a produtividade das lavouras. Futuramente esta prática poderá ser disseminada para toda a localidade em questão, já que nenhum dos moradores conhecia o termo biogás até então, sequer do possível aproveitamento do esterco bovino para sua produção, resultando em energia térmica e elétrica. O interesse resultou apenas depois de esclarecidas as dúvidas, mostrando interesse no projeto.

Além disso, a queima do metano reduz as emissões de GEE (Gases de Efeito Estufa) e, de acordo com Barbieri (2004), essa queima gera o direito de Certificados de Reduções de Emissões (RCEs) - um título negociável no mercado de carbono mundial, ou seja, o agropecuarista ao retirar esses gases da atmosfera tem a possibilidade de comercializar os créditos de carbono, cada tonelada equivalendo a um crédito de carbono.

Vale a pena ressaltar que, mesmo sem mostrar a viabilidade através de números, deve-se levar em conta a quantidade de esterco bovino emitida diariamente e a quantidade residências próximas, mostrando a viabilidade de instalação do projeto, visto que este providencia um melhor destino aos dejetos sem tratamento que são lançados diretamente no solo, uma questão de higiene e de caráter ambiental. 


\section{CONTRIBUIÇÃO TECNOLÓGICAS E INOVADORAS}

As temáticas da Gestão Ambiental configuram-se na atualidade como imprescindíveis para o desenvolvimento científico e tecnológico mundial. Particularmente no campo das Ciências Sociais Aplicadas e especificamente naquelas com as quais o presente projeto dialoga de forma mais evidente, ou seja, Ciências Contábeis e Administração (Gestão), Engenharia (Tecnologia) quando se fala em contribuição científica e tecnológica há uma interpenetração desses três sentidos nas práticas de pesquisa, que se manifestam a partir da própria natureza e do conhecimento destes campos disciplinares.

Segundo a WBCSD (2008) a utilização de tecnologias mais precisas contribui para uma aplicação contínua de estratégica técnica, ambiental e econômica que estão integradas a processos, serviços e produtos, a fim de aumentar a eficiência de uso dos recursos naturais e diminuir resíduos jogados no meio ambiente. A aplicação de tecnologias inovadoras é uma estratégica que emerge numa redução, ou até eliminação, de qualquer fonte de poluição e na racionalização dos recursos naturais.

A decomposição e estabilização dos resíduos sólidos ocorrem na natureza desde que surgiu o planeta. Com o avanço da civilização e os avanços científicos, vários esforços estão sendo feitos para racionalizar e controlar o processo de poluição do meio ambiente, de forma a torná-los mais eficazes e eficientes (MEFGI, 2007).

Assim, a proposta deste projeto é inovadora, pois, além de tomar como base o caráter científico, apresent caráter tecnológico, já que o desenvolvimento desse biodigestor busca utilizar de materiais recicláveis, contribuindo com a consolidação do tão sonhado desenvolvimento sustentável.

\section{CONCLUSÃO}

O trabalho demonstrou viabilidade técnica da implantação de biodigestor para a produção de biogás em propriedade rural, utilizando esterco bovino como insumo, produzindo produtos e subprodutos que serão aproveitados pelo pequeno produtor e proporcionando o aumento de renda da propriedade, bem como as vantagens ambientais a um custo mínimo.

Foi ainda empreendida uma hipótese "Será que os modelos de biodigestores disponíveis na literatura utilizam materiais recicláveis na sua estrutura, e seus custos de instalação são apropriados para agricultura familiar?", a ser averiguada sua veracidade. Assim, seguindo os procedimentos metodologicos, foi obtido um modelo de biodigestor de baixo custo, que utiliza materiais recicláveis e portátil, confirmando que a hipotese.

A partir desse experimento, outros estudos mais detalhados poderão ser desenvolvidos, como o cálculo de volume do biodigestor e a produção do biogás, que permitirá conhecer se a quantidade produzida é suficiente para abastecer uma residência. Outra questão a ser estudada é a geração de energia elétrica através de esterco bovino, visto que este é altamente renovável e sustentável, resultando em uma economia e incentivando pesquisas que sejam disseminadoras de conhecimentos e novas tecnologias.

Conclui-se que a produção de biogás, biofertilizante e adubo orgânico obtido a partir de biodigestores é de fácil utilização e de fácil acesso, podendo contribuir de forma eficaz e eficiente, tanto do ponto de vista ambiental quanto social. Além disso, podem-se obter menores índices de emissões de gases poluentes, minimização de doenças e incentivo econômico e, principalmente, a economia proporcionada ao agricultor familiar que possui esse tipo de tecnologia.

\section{REFERÊNCIAS}

ANDREOLI, C. V: Gestão Ambiental. Coleção Gestão Empresarial. Faculdades de Bom Jesus. Economia Empresarial / Fae Business school. Curitiba: Associação Franciscana de Ensino Senhor Bom Jesus, (2002).

BANCO MUNDIAL, FINEP \& BM\&FBOVESPA; Levantamento de oportunidades concretas de projetos de baixo carbono no Brasil; (2010). Acesso: http://www.bmfbovespa.com.br/pt-br/mercados/download/Levantamento-de-Oportunidades-Concretas-de-Projetos-de-Baixo-Carbono-no-Brasil.pdf (2012).

BASTOS ALVES, J. A.; GONCALVES, A. C.; BRAUN, M. B. S.; Mercado de créditos de carbono e a ati- 
vidade suinícola: uma análise do projeto de MDL da Sadia. In: VI Encontro de Economia Paranaense - VI ECOPAR, 2008, Ponta Grossa. Anais do VI Encontro de Economia Paranaense -VI ECOPAR (CD-ROM), (2008).

BERNSTORFF, C.; Créditos de Carbono e Mecanismo de Desenvolvimento Limpo - MDL: Captura de Metano no Tratamento de Dejetos Suínos; Pós-Graduação em Engenharia do Meio Ambiente, da Faculdade de Engenharia, da Universidade do Estado do Rio de Janeiro. Área de concentração: Mestrado Profissionalizante em Engenharia Ambiental (2009).

CENTRO DE ESTUDOS AVANÇADOS EM ECONOMIA APLICADA (CEPEA). Estudo dos Impactos Econômicos da Adequação Ambiental da Suinocultura. Piracicaba; 99 p.; (2006).

CONEJERO, M. A.; O credito de carbono do Protocolo de Kyoto como Commodity Ambiental. Aquecimento Global e créditos de carbono- Aspectos Jurídicos e técnicos. São Paulo, (2007).

DINIZ, ELIEZER M.; BERMANN, CELIO; Economia verde e sustentabilidade; Estudos Avançados, vol.26 nº.74 São Paulo (2012).2/documents/cneg4/anais/T7_0035_0236.pdf > Acesso em: 31 mar, 2014.

DIAS, R. Gestão Ambiental: Responsabilidade Social e Sustentabilidade. São Paulo: Editora Atlas S.A., 2009.

DONAIRE, D. Gestão Ambiental na Empresa. $2^{\circ}$ Ed. São Paulo, Editora Atlas S.A., 2009.

GIL, A. C. Estudo de Caso. São Paulo: Atlas, 2009.

Como elaborar projetos de pesquisa. $4^{\circ}$ ed. São Paulo: Atlas, 2008.

GOMES, A. F.; JABBOUR, C. J. C.; FREITAS, W. R. S. Gestão Ambiental: Um novo desafio para os profissionais de recursos humanos? Revista Cesumar - Ciências Humanas e Sociais Aplicadas, v. 16, n. 1, jan./jun. 2011, p. 29-47. Disponível em: <http://www.cesumar.br/pesquisa/periodicos/index.php/revcesumar/article/ viewFile/1176/1215> Acesso em: 31 de mar, 2014.

KÖCHE, J. C. Fundamentos de metodologia científica: teoria da ciência e prática da pesquisa. 15. Ed. Petrópolis, RJ: Vozes, 1997.

KRAEMER, T. H. Modelo Econômico de Controle e Avaliação de Impactos Ambientais - MECAIA. 2002. 191f. Tese (Doutorado) - Universidade Federal de Santa Catarina, Florianópolis, 2002.

YIN, R. K. Estudo de Caso: planejamento e métodos. $3^{\circ}$ Ed. Porto Alegre: Bookman, 2005.

MARCONI, M. A.; LAKATOS, E. M. Fundamentos de Metodologia Científica. $7^{\circ}$ Ed. São Paulo, Editora Atlas S.A., 2010.

Fundamentos de Metodologia Científica. 6 Ed. São Paulo, Editora Atlas S.A., 2007.

NAIME, R. H.; ANDARA, S.; SANTOS, K. L. Benefícios da implantação do Sistema de Gestão Ambiental na Indústria. Revista Cesumar - Ciências Humanas e Sociais Aplicadas, v. 15, n. 1, jan./jul. 2010, p. 11-33. Disponível em: <http://www.cesumar.br/pesquisa/periodicos/index.php/revcesumar/article/viewArticle/1063> Acesso em: 31 mar, 2014.

OLIVEIRA, O. J. ; PINHEIRO, C. R. M. S. Implantação de sistemas de gestão ambiental ISO 14001: uma contribuição da área de gestão de pessoas. Revista Gestão \& Produção, São Carlos, v. 17, n. 1, p. 51-61, 2010. Disponível em: < http://www.scielo.br/pdf/gp/v17n1/v17n1a05.pdf> Acesso em: 31mar, 2014.

REIS, L. F. S. de S. D.; QUEIROZ, S. M. P. Gestão Ambiental em Pequenas e Médias Empresas. $1^{\circ}$ Ed. Rio de Janeiro, Editora Norte Rio Gráfica, 2002. 
SOUZA, N. G.; PASQUALETTO, A. ; RESENDE, V. Abordagem Sistêmica da Implantação da Nbr Iso 14001 na Concessionária Lince Veículos Sa - Goiânia. Disponível em <http://www.ucg.br/ ucg/prope/cpgss/ArquivosUpload/36/file/Continua/ABORDAGEM\%20SIST\%C3\%8AMICA\%20 DA\%20IMPLANTA $\%$ C3\%87\%C3\%83O\%20DA\%20NBR\%20ISO $\% 2014001 \% 20$ NA $\% 20$ CONCESSION\%C3\%81RIA\%20LINCE\%20VE\%C3\%8DCULOS_.pdf > Acesso em: mar, 2014.

TACHIZAWA, T. Gestão Ambiental e Responsabilidade Social Corporativa: Estratégias de Negócios Focadas na Realidade Brasileira. $6^{\circ}$ Ed. São Paulo, Editora Atlas S. A., 2009.

TRIVIÑOS, A. N. S. Introdução à Pesquisa em Ciências Sociais: A Pesquisa Qualitativa em Educação. $1^{\circ}$ Ed. São Paulo, Editora Atlas S. A., 2007.

WENDLER, D. F. Sistema de Gestão Ambiental Aplicado a uma Vinícola: Um Estudo de Caso. 2009. 176 f. Dissertação (Mestrado) - Universidade Federal de Santa Maria, Santa Maria, 2009. Disponível em: < http:// www.senairs.org.br/cntl/ > Acesso em: 26 set. 2010, 13:56.

RELATÓRIO DO ESTADO DO MEIO AMBIENTE 2013. Rea 2013: Portugual. Portugual, 2013, p. 185. Disponível em: < http://www.apambiente.pt/_zdata/DESTAQUES/2013/REA_2013_Final_30dezembro. pdf > Acesso em: 21 jan. 2014.

TRIGUEIRO, A. Mundo sustentável: abrindo espaço na mídia para um planeta em transformação. Rio de Janeiro: Globo, 2005. p. 102. 